\title{
Les troubles du récit. Pour une nouvelle approche des processus narratifs
}

Jean-Marie Schaeffer (2020).

París: Thierry Marchaisse, 200 páginas.

ISBN 9782362802393.

\section{(4) Victoria García}

Universidad de Buenos Aires, Facultad de Filosofía y Letras, Instituto de Filología y Literaturas Hispánicas “Dr.

Amado Alonso" - Consejo Nacional de Investigaciones Científicas y Técnicas, Argentina

victoriaggarcia@gmail.com

Dos son los trazos que signan la obra del filósofo francés Jean-Marie Schaeffer desde sus inicios en los años 80 hasta hoy: la inclinación por pensar los grandes objetos de la teoría literaria y la estética -los géneros literarios, la ficción, la experiencia estética-, y un estilo argumentativo erudito y preciso, que recupera tanto los ideales de rigor y claridad de la filosofía analítica como la minuciosidad descriptiva de uno de sus grandes maestros, Gérard Genette. Los trabajos de Schaeffer construyen imaginariamente el escenario de la discusión que instauran al anticipar posibles objeciones y refutarlas o relativizarlas con sagacidad notable, dejando así, en apariencia, escaso margen para la polémica.

En el ámbito hispanoamericano, fue paradójicamente un trabajo surgido de una polémica el que consolidó el lugar de Schaeffer como exponente de la disciplina literaria actual: nos referimos a Pequeña ecología de los estudios literarios. ¿Por qué y cómo estudiar la literatura?, publicado en 2011 en Francia y traducido al castellano dos años después. La polémica que dio lugar al libro tenía por objeto una supuesta crisis de la literatura, que, según lo diagnosticaban entonces autores como Tzvetan Todorov, Antoine Compagnon e Yves Citton, perdía vitalidad en las sociedades contemporáneas, debido a la expansión vertiginosa de expresiones culturales vinculadas con los mass media. En su Pequeña ecología, Schaeffer interviene en esta polémica, a la vez que procura atemperarla, como lo señaló Jerónimo Ledesma (2013) a propósito del libro: con su habitual estilo escrupuloso y metódico, sostiene allí que, en rigor, lo que está en crisis no es la literatura sino una cierta representación de lo literario instalada en las instituciones de enseñanza e investigación francesas. Es posible hipotetizar que esta polémica mitigada sobre la crisis de la literatura y/o de los estudios literarios volvió legible a Schaeffer desde América Latina y desde la Argentina en particular, donde hacer teoría y crítica literaria sin polemos parece constituir una contradicción en sus términos.
La Pequeña ecología forma parte de las intervenciones con las que Schaeffer ha buscado responder a una encrucijada epistemológica que concierne no solo a los estudios literarios y a la teoría de las artes, sino a las humanidades en general. Con particular fuerza programática desde los años 2000, el autor ha desplegado un proyecto filosófico que se reclama naturalista y que, en esa línea, interroga las bases mismas de la concepción de lo humano y lo social. Schaeffer impugna el dualismo naturaleza/cultura y la "ruptura óntica" que, según denuncia, ha escindido a los seres humanos de los otros seres vivos en el pensamiento filosófico moderno, desde el cogito cartesiano en adelante (2009). En textos referidos a problemas de arte y estética, como Adiós a la estética (2005 [2000]), ¿Por qué la ficción? (2002 [1999]) y La experiencia estética (2018 [2015]), puntualiza las nociones fundamentales de este programa naturalista aplicado a lo que denomina la relación estética -retomando la terminología utilizada por Genette en L'œuvre de l'art- o la experiencia estética. Estos conceptos describen, para el autor, un tipo de actividad cognitiva autoteleológica, i.e., orientada por la meta de obtener satisfacción de la misma experiencia de conocimiento -como sucede, de forma privilegiada, en la ficción-. En tanto actividad cognitiva, la experiencia estética puede ser considerada, según él, desde el punto de vista de las condiciones culturales en las que tiene lugar, así como en relación con ciertas disposiciones biológicas universales que permitirían el desarrollo estos comportamientos, más allá de las particularidades culturales: "el cerebro humano es capaz de proceder a una activación neuronal de la atención cognitiva regulada por su índice de satisfacción interno", sostiene en Adiós a la estética (Schaeffer, 2005: 66).

La apuesta de Les troubles du récit, publicado en 2020 por Thierry Marchaisse, no se comprende cabalmente sino dentro de este derrotero teórico del autor. El punto de partida de Schaeffer es clásico: retoma a Barthes para interrogar el aparente contraste entre 
la "variedad prodigiosa" de los relatos y su condición universal, que trasciende las épocas y los contextos culturales. La vía que adopta para explorar este problema, sin embargo, es inusual: elige aproximarse al fenómeno de la narratividad partiendo no del análisis de relatos literarios ni, más en general, de discursos narrativos públicos, sino del examen de procesos cognitivos en los que la narración apenas se insinúa o se despliega incipiente, incluso distorsionada. Schaeffer sostiene que el estudio de estas formas límite de la narratividad posibilita echar luz sobre sus modalidades canónicas. Invita, así, a una articulación epistemológica entre la narratología y los estudios cognitivos, aun cuando no deja de reconocer los problemas que ese diálogo involucra, especialmente en el plano metodológico (p. 39): las investigaciones narratológicas suelen prescindir de una validación empírica que, en cambio, en el enfoque psico-cognitivo resulta crucial.

El concepto de proto-narratividades ("Proto-narrativités”, abordado en el capítulo homónimo) se encuentra en la base del modo en que el autor propone acercarse a los fenómenos narrativos. Se trata de una forma particular de organización o procesamiento de las representaciones mentales, previa a la narración -entendida como acto comunicativo-y al relato -es decir, a la obra narrativa materializada como tal-. La memoria personal episódica, la planificación y la imaginación de la acción, el pensamiento causal espontáneo y la actividad onírica están comprendidos, para Schaeffer, en el territorio de los procesos proto-narrativos. En todos los casos, se trata de encadenamientos de representaciones agentivas (acciones) o no agentivas (acontecimientos), que involucran una orientación temporal y un perspectivismo intrínseco. Si el primero de estos elementos puede resultar obvio, el segundo no lo es tanto: Schaeffer postula, en esta línea, que el punto de vista no es una opción de estructuración narrativa entre otras, sino que es constitutivo de la narratividad. El enfoque experiencial a partir del cual se organiza el contenido narrativo a nivel mental es siempre el de una primera persona que lo produce, ya en forma voluntaria o involuntaria.

La noción de proto-narratividad le permite a Schaeffer instituir un territorio cognitivo propio de la narración, relativamente autónomo respecto de otros dos dominios que, en el discurso teórico, a menudo han sido asociados estrechamente o incluso asimilados al relato: el lenguaje verbal, por un lado, y la ficción, por otro.

La relación entre narratividad y lenguaje verbal es considerada en el capítulo "Dysnarrativités", centrado en desórdenes cognitivos que trastornan o bloquean la facultad de comprender y producir narraciones. El autor revisa allí una serie de investigaciones sobre las implicaciones neurológicas de los procesos narrativos y sus disfunciones: la subnarrativización (undernarration) -incapacidad para construir narraciones contrafactuales-, la des-narrativización (denarration) -incapacidad para elaborar relatos sobre experiencias, acciones y deseos- y la narrativización descontrolada (unbounded narration) -incapacidad para distinguir entre hechos y ficción en la construcción de la memoria episódica-. Schaeffer señala que todos estos desórdenes se ligan con fenómenos de despersonalización más o menos graves, lo cual demuestra la importancia de los procesos cognitivos asociados a la narración en la configuración de la identidad personal. El autor afirma, a la vez, que no existe interdependencia entre estas disfunciones y las afasias, que afectan el procesamiento del lenguaje verbal: se puede padecer de alguna forma de disnarratividad sin perder habilidades lingüísticas, y a la inversa. Esto lleva a la necesidad de reconsiderar la idea vastamente asumida de que la narratividad es inherentemente un proceso verbal.

Schaeffer avanza en la indagación de este problema en el capítulo "Raconter sans mots?", dedicado al estudio de la narratividad visual. Allí examina la posibilidad de que las imágenes fijas aisladas, no fotográficas pero figurativas, contengan una dimensión narrativa. Según el autor, la tesis de que la pintura no puede representar acontecimientos es inexacta: en rigor, puede hacerlo mostrando un momento específico del desarrollo de un evento. Si el pintor tiene talento, elegirá un momento capaz de reenviar alusivamente a toda la secuencia temporal; por eso Schaeffer argumenta que una imagen puede representar más de lo que muestra. El autor plantea, además, que situándose desde la recepción la narratividad es ineludible, no solo porque atravesar un cuadro con la mirada implica una temporalidad, sino además -y sobre todo- porque los signos visuales ponen en movimiento nuestra imaginación: más específicamente, operan como catalizadores de un proceso de simulación que vivifica en la mente del espectador la secuencia temporal cifrada en una imagen.

La relación entre relato y ficción se aborda en los dos últimos capítulos del libro. En "Entre récit factuel et fiction: mouvements transfrontaliers", Schaeffer retoma algunas de las reflexiones plasmadas en ¿Por qué la ficción?, para complejizarlas en una dimensión específica: la que concierne a las fronteras y traspasos entre el relato ficcional y el factual. Sin negar la importancia de esa distinción conceptual, “empiriquement 
irréfutable, mais encore indispensable pour éviter la déstabilisation cognitive et éthique de notre rapport au monde et à autrui" (p. 123), el autor se propone indagar los solapamientos y las transgresiones que tornan porosas las fronteras entre una y otra modalidad narrativa. No lo hace desde la perspectiva de las violaciones voluntarias de los límites genéricos, ni considerando los errores pragmáticos que llevan a los receptores a interpretar en forma distorsionada los propósitos comunicativos del autor -como ocurrió, célebremente, en el caso de la biografía ficticia Marbot, crucial para el Schaeffer de ¿Por qué...?-. En cambio, el autor se detiene en el examen del estatuto mismo de las representaciones, partiendo del supuesto de que no existe diferencia ontológica entre las contenidas en un relato factual y en uno ficcional: más bien, la distinción se ubica en el plano pragmático, relativo al uso y a la actitud epistémica que se adopta frente a las representaciones en cada caso. El planteo podría carecer de originalidad si Schaeffer no lo complementara con una reflexión, inspirada en David Hume, sobre la naturaleza de las creencias y su relación con el procesamiento cognitivo de las ficciones. Creer, señala Schaeffer, es cognitivamente menos costoso que no creer; por eso la ficción, como actitud intencional que tuerce nuestra tendencia natural a transformar todas las representaciones en creencias, es una verdadera conquista cultural. Sin embargo, esa frontera no es impermeable. Schaeffer apela en este punto a estudios de psicología cognitiva para sostener que, en la recepción de relatos ficcionales, lo habitual es la oscilación entre la compartimentación de la información ficticia y su integración al espacio de las creencias. Todo esto lleva a reafirmar, una vez más, la tesis de la proto-narratividad, es decir, la existencia de un arché proto-narrativo neutral respecto de la distinción entre lo factual y lo ficcional, dos lógicas pragmáticas que resultarían de una disociación secundaria y relativamente frágil.

Schaeffer distingue, así, (proto-)narratividad de ficción. En "De quelques formes d'imagination proto-narrative”, partirá de una distinción entre esos dos conceptos y el de imaginación, para examinar un dominio específico de los recursos imaginativos: el de la imaginación propositiva y descriptiva del futuro (prospecciones y proyecciones) y del pasado (retroacciones y retrospecciones). Mientras que la ficción implica siempre una dimensión intersubjetiva y un arraigo en convenciones culturales aprendidas, las construcciones de la imaginación que aborda aquí Schaeffer se asocian a procesos mentales endógenos, activados por la incidencia de una constelación emocional y, a la vez, productores de emociones ellos mismos. Se trata de actividades cognitivas performativas, en los que la simulación mental, entendida como transporte experiencial del yo en un yo imaginado, induce reordenamientos en el dominio de nuestra realidad. Una vez más, la frontera entre lo real y lo imaginado -en este caso, no ficticiose vuelve porosa.

Schaeffer busca ampliar, a lo largo del libro, la concepción tradicional de los fenómenos narrativos, que tiende a identificar los rasgos de algunas de sus cristalizaciones culturales, en especial los relatos ficticios, con los de la narratividad como tal. El interrogante que surge de su enfoque es, como él mismo lo prevé, metodológico: el autor elabora sus conceptualizaciones sobre la base de múltiples recursos, que incluyen el examen analítico de textos clásicos del pensamiento filosófico, la revisión bibliográfica de trabajos recientes en psicología cognitiva, la ejemplificación con obras literarias y artísticas canónicas, y hasta la introspección en sus propios procesos cognitivos. Uno de los momentos memorables del libro es la evocación de la muerte de su padre, quien cayó por las escaleras del sótano de su casa, en un episodio que para el autor constituyó un motivo de imaginación retrospectiva durante muchos años:

\section{Cela m'a permis d'apprendre qu'il y a autant de manières différentes d'imaginer la mort qu'il y en a de mourir, c'est-à-dire un très grand nombre. Mais pas un nombre infini: mon imagination a fini par parcourir toutes les variantes possibles. Et mon esprit, comme rassuré par le fait que désormais aucun nouvel aspect non envisagé ne pouvait se tapir quelque part, a fini par intégrer la mort de mon père dans le monde de ma vie, par me la rendre familière. À tel point que je peux désormais m'adresser à lui (en imagination?) et lui dire en rigolant: " Faut-il être bête pour mourir comme cela! » (p. 176).}

La evocación autobiográfica refuerza la argumentación del autor tanto en lo estético -por lo poderoso de la escena- como en lo epistemológico, ante las dificultades que plantea, como él mismo lo reconoce, la investigación sobre procesos cognitivos y sobre el vínculo entre aquellos y la actividad neurológica (p. 79).

La multiplicidad de herramientas analíticas que recoge Schaeffer da cuenta de una apuesta transdisciplinaria que, como indicamos al comienzo, busca naturalizar la investigación en ciencias humanas y sociales. El programa es ambicioso. Su consecución, por eso, parecería requerir esfuerzos grupales e institucionales diversos, más allá del tesón analítico y la sutileza conceptual que en esta última empresa teórica vuelve a demostrar Schaeffer. 


\section{Bibliografía}

"Ledesma, J. (2013). "La academia literaria en debate. Reseña sobre Pequeña ecología de los estudios literarios de Jean-Marie Schaeffer". Exlibris, 2, 244-254. En: http://revistas.filo.uba.ar/index. php/exlibris/article/view/389/258; obtenido el 20/11/2020.

"Schaeffer, J.-M. (2005). Adiós a la estética. Madrid: La balsa de la Medusa.

»Schaeffer, J.-M. (2009). El fin de la excepción humana. Buenos Aires: Fondo de Cultura Económica. 